\title{
The Annual Meeting of the German Society of Neuroradiology Cologne, October 10th to 12th, 2013
}

\author{
A. Doerfler
}

Received: 14 May 2013 / Published online: 25 May 2013

(C) Springer-Verlag Berlin Heidelberg 2013

Dear Colleagues and friends of neuroradiology,

Welcome to neuroRAD, the Annual Meeting of the German Society of Neuroradiology (DGNR), which has become the largest European meeting in the field of neuroradiology. Embedded in a unique and inspiring ambience and with its characteristic mix of teaching and scientific presentations, workshops, satellite symposia, and key note lectures, neuroRAD provides an innovative and comprehensive update on diagnostic and therapeutic neuroradiology. This year's 48th Annual Meeting of the German Society of Neuroradiology will be held in cooperation with our partner society the Austrian Society of Neuroradiology (ÖGNR).

Addressing the very current discussions on interventional stroke therapy this year's main "interventional" topic is again intra-arterial stroke therapy with a focus on evidence and (the upcoming) randomized trials, supplemented by an update on current endovascular aneurysm treatment.

With imaging technology, rapidly evolving "medical technology" is a further topic of the congress. The focus here is on state-of-the-art imaging, fascinating innovative modalities, i.e., high-field magnetic resonance imaging (MRI), metabolic and hybrid imaging techniques, flat-panel angiography/computed tomography (CT) with regard to clinical work-flow and decision-making, respectively. Further major topics of neuroRAD 2013 are metabolic and inflammatory central nervous system (CNS) disease and epilepsy.

A. Doerfler $(\bowtie)$

Neuroradiologie, Universitätsklinikum Erlangen,

Schwabachanlage 6 (Kopfklinikum), 91054 Erlangen, Germany

e-mail: arnd.doerfler@uk-erlangen.de
A highlight of the congress will certainly be the teaching lecture given by Anne Osborn (Salt Lake City). Amongst others, renowned international speakers, i.e., D. Prayer (Vienna), Ch. Strother (Madison), J. Byrne (Oxford), and F. Barkhof (Amsterdam) will supplement the program by dedicated key note lectures in their field of expertise. Traditionally, the popular session "What's new in neuroradiology?" and interactive case sessions (including TED) will round up a comprehensive program.

Last but not least, a major component of neuroRAD 2013 is the dedicated program for radiology technicians, whose skills significantly contribute to the quality and added value of neuroradiology, and without whom we would be lost.

Abstract submission is already open. For further information on neuroRAD 2013 please visit our website www. dgnr2013.de.

The German and Austrian Societies of Neuroradiology would like to welcome you as a participant at its upcoming meeting from October 10th to 12th, 2013 in Cologne.

Arnd Doerfler

Congress President neuroRAD 2013

Michael Knauth

President German Society of Neuroradiology

Johannes Trenkler

Congress President ÖGNR 